\title{
Study of Efficacy of Sevoflurane with Rocuronium during Induction in Neurosurgical Patients
}

\author{
Jose B Cherayath ${ }^{1}$, Jitin George ${ }^{2}$ \\ ${ }^{1}$ Associate Professor, Department of Anaesthesia, P K Das Medical College, Vaniyamkulam, Ottapalam, Palakkad, Kerala-679522, India, ${ }^{2}$ Assistant \\ Professor, Department of Anaesthesia, P K Das Medical College, Vaniyamkulam, Ottapalam, Palakkad, Kerala-679522, India.
}

\section{Abstract}

Background: Rocuronium provides good intubating conditions but large doses causes prolongation of its duration of action, making it unsuitable for short surgical procedures. Aims: We assessed the efficacy of sevoflurane with rocuronium during induction in terms of reducing the onset time for intubation, evaluating intubating conditions and haemodynamic responses during intubation. Subjects and Methods: This prospective, randomised, double-blind study was conducted in 40 adult patients undergoing lumbar disc operations under general anaesthesia were randomly allocated into two equal groups namely Group R (received $0.8 \mathrm{mg} / \mathrm{kg}$ of rocuronium) and Group RS (received $0.8 \mathrm{mg} / \mathrm{kg}$ of rocuronium and $2 \%$ sevoflurane during induction). Results: The two groups were comparable with respect to age, sex, weight and ASA grade. The time for loss of thumb adduction was $101.4 \pm 11.2 \mathrm{~s}$ in Group R compared with $61.04 \pm 5.4 \mathrm{~s}$ in Group RS P $<0.001]$. The onset time of intubation was significant $\mathrm{P}<0.001]$. Significant differences in heart rate and mean arterial pressure were seen immediately after intubation, at 1 and 3 min after intubation $(\mathrm{P}<0.05)$ between the two groups. The mean intubation score was comparable in both the groups is insignificant $[\mathrm{P}=0.11]$. Conclusion: Rocuronium $0.8 \mathrm{mg} / \mathrm{kg}$ along with $2 \%$ sevoflurane provides rapid sequence intubation during anaesthesia in neurosurgical patients.

Keywords: Sevoflurane, Rocuronium, Haemodynamic responses.

Corresponding Author: Dr. Jitin George, Assistant Professor, Department of Anaesthesia, P K Das Medical College, Vaniyamkulam, Ottapalam, Palakkad, Kerala-679522, India.

Email: jitingorge989@gmail.com

Received: January 2020

Accepted: January 2020

\section{Introduction}

Endotracheal intubation using succinylcholine is an established technique for rapid sequence intubation in patients at risk of gastric aspiration. Succinylcholine has a number of undesirable side effects like hyperkalaemia, bradyarrhythmias, increased intraocular tension, increased intracranial tension, ${ }^{[1]}$ malignant hyperthermia and masseter spasm. Hence, it is not suitable in conditions like neuromuscular disorders, burns, acute head injury, ${ }^{[2]}$ open eye injury, intracranial haemorrhage spinal cord injury ,cerebrovascular accidents and renal disease. ${ }^{[3]}$

Rocuronium is an aminosteroid NDMR with rapid onset and intermediate duration of action. It has a faster neuromuscular blockade onset time compared to other NDMRs. ${ }^{[4]}$ It provides clinically acceptable intubating conditions within $60-90 \mathrm{~s}$ in dose range of $0.6-1.2 \mathrm{mg} / \mathrm{kg},{ }^{[5]}$ but large doses unduly prolong its duration of action, making it unsuitable for short surgical procedures. Hence, it may not be preferable for rapid sequence induction and endotracheal intubation. Volatile anaesthetics are known to potentiate the effects of NDMRs. ${ }^{[6]}$ We used $2 \%$ sevoflurane with rocuronium bromide (at intubating dose of $0.8 \mathrm{mg} / \mathrm{kg}$ ) during induction in patients undergoing elective lumbar disc surgeries under general anaesthesia.

\section{Subjects and Methods}

This prospective, randomised, double-blind study was conducted after Institute Ethics Committee approval from local review board with valid, written, informed consent from patients. Study carried out at Department of Anesthesia in 40 adult patients undergoing lumbar disc operations under general anaesthesia were randomly allocated into two equal groups namely Group R (received $0.8 \mathrm{mg} / \mathrm{kg}$ of rocuronium) and Group RS (received $0.8 \mathrm{mg} / \mathrm{kg}$ of rocuronium and $2 \%$ sevoflurane during induction).

\section{Inclusion criteria:}

Patients belonging to American Society of Anesthesiologists (ASA) physical status Grades 1 and 2 aged between 30 and 65 years, of either gender.

\section{Exclusion criteria:}

Patients with neuromuscular diseases, anticipated difficult intubation, pregnancy and breastfeeding, hepatic, renal diseases, patients with neuromuscular disorders, patient on drugs that affect neuromuscular block and pregnant and lactating mothers history of allergic reaction to rocuronium and psychiatric patients. 
TOF was used for neuromuscular monitoring. The chosen hand was cleaned with spirit over the area around the ulnar nerve and the thumb. Two surface electrodes were applied over the ulnar nerve at the wrist and transducer was applied to ipsilateral thumb. In the operation theatre routine standard monitors were attached. $18 \mathrm{G}$ intravenous line was secured and a drip of ringer lactate started. Patients were preoxygenated with 100 percent oxygen at a flow rate of 6 $\mathrm{L} / \mathrm{min}$ for $3 \mathrm{~min}$. After the loss of verbal response, a supramaximally set TOF stimulus was applied to the ulnar nerve at the wrist through surface electrodes (stimulation current set at $50 \mathrm{~mA}$ ) and baseline TOF ratio percentage was noted. After giving an intubating dose of rocuronium 0.8 $\mathrm{mg} / \mathrm{kg}$, supramaximally set TOF stimulus was again applied and repeated every $15 \mathrm{~s}$ to evaluate visually for loss of adduction of thumb and disappearance of the first response (T1) of TOF stimuli. Onset time of intubation was taken as the time interval between the intubating dose and the loss of T1 of TOF stimuli. Intubating conditions were graded as excellent when intubating scores were between 8 and 9, good with 6-7, fair with 3-5 and poor with 0-2. Excellent and good intubating conditions were considered clinically acceptable as per Cooper et al. ${ }^{[7]}$

Data noted included loss of thumb adduction, onset time of intubation, conditions at the time of intubation (using Cooper's scoring system), heart rate, mean arterial pressure, oxygen saturation (using pulse oximetry) at baseline, postinduction, at intubation, immediately after intubation, $1 \mathrm{~min}$, $3 \mathrm{~min}$ and $5 \mathrm{~min}$ after intubation.

The observations were recorded in Microsoft excel spread sheet and analysis was done using the SPSS 21 software. A P value $<0.05$ was considered significant. Data noted includes loss of thumb adduction, onset time of intubation and conditions at the time of intubation (using Cooper's scoring system). Continuous measurements were presented as mean \pm standard deviation (SD) used for comparing intubating conditions among the groups and demographic data.

\section{Results}

All 40 patients completed the study and following results were obtained.

Table 1: Demographic details in both groups of study

\begin{tabular}{|l|l|l|l|}
\hline $\begin{array}{l}\text { Demographic } \\
\text { data }\end{array}$ & Group-R & Group-RS & P-Value \\
\hline Age (in years) & $50.6+10.1$ & $49.4+9$ & $>0.05$ \\
\hline Gender(M:F) & $10: 10$ & $11: 9$ & $>0.05$ \\
\hline Weight & $59.2+13.1$ & $60.5+13.9$ & $>0.05$ \\
\hline $\begin{array}{l}\text { ASA Grade I } \\
\text { and II }\end{array}$ & $15: 5$ & $16: 4$ & $>0.05$ \\
\hline $\begin{array}{l}\text { Duration of } \\
\text { surgery (min) }\end{array}$ & $45+7.8$ & $47+8.1$ & $>0.05$ \\
\hline $\begin{array}{l}\text { Duration of } \\
\text { anesthesia (min) }\end{array}$ & $50.4+8.9$ & $51.4+9.1$ & $>0.05$ \\
\hline
\end{tabular}

The two groups were comparable with respect to age, sex, weight and ASA grade with $\mathrm{P}$ value $>0.05$.

The time for loss of thumb adduction was $101.4 \pm 11.2 \mathrm{~s}$ in Group R compared with $61.04 \pm 5.4 \mathrm{~s}$ in Group RS P < $0.001]$. The onset time of intubation was $102.65 \pm 10.1 \mathrm{~s}$ in
Group R compared with $59.6 \pm 4.1 \mathrm{~s}$ in Group RS P $<0.001]$.

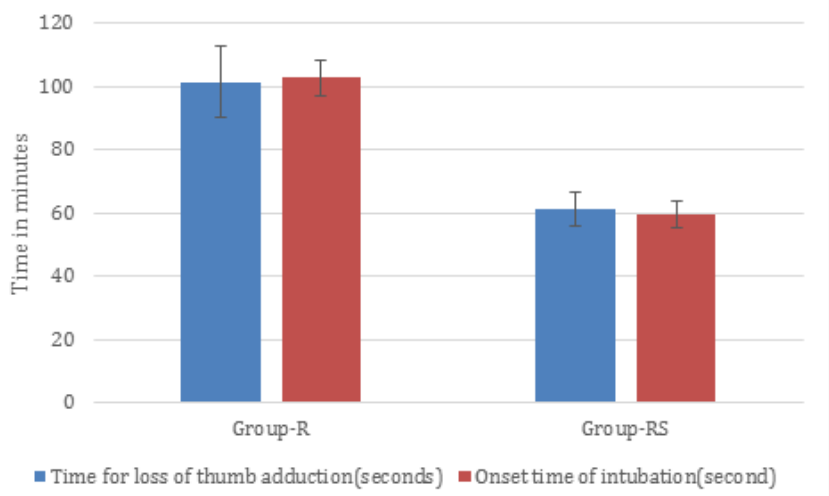

Figure 1: Neuromuscular monitoring data

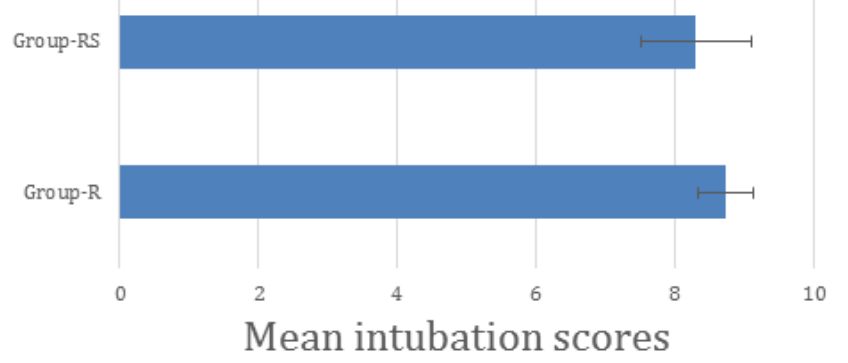

Figure 2: Mean intubation score (mean \pm standard deviation)

Mean intubation score is insignificant when compared in both groups.

Table 2: Comparison of changes in Systolic blood pressure between the groups.

\begin{tabular}{|l|l|l|l|}
\hline Time & Group-R & Group-RS & P-Value \\
\hline Basal & $96+8.1$ & $94+8.4$ & $>0.05$ \\
\hline Post induction & $90+7.1$ & $83+7.2$ & $>0.05$ \\
\hline At intubation & $90+7.2$ & $83+7.1$ & \\
\hline $\begin{array}{l}\text { Immediately } \\
\text { after intubation }\end{array}$ & $99+6.1$ & $91+6.8$ & \\
\hline $\begin{array}{l}1 \text { min after } \\
\text { induction }\end{array}$ & $98+5.4$ & $91+7.2$ & $>0.05$ \\
\hline $\begin{array}{l}3 \text { min after } \\
\text { induction }\end{array}$ & $97+6.7$ & $89+6.5$ & $>0.05$ \\
\hline $\begin{array}{l}5 \text { min after } \\
\text { induction }\end{array}$ & $92+9.5$ & $92+7.3$ & $>0.05$ \\
\hline
\end{tabular}

Table 3: Comparison of changes in Heart rate between the groups.

\begin{tabular}{|l|l|l|l|}
\hline Time & Group-R & Group-RS & P-Value \\
\hline Basal & $88+5.5$ & $86+5.4$ & $>0.05$ \\
\hline Post induction & $87+5.7$ & $86+6.2$ & $>0.05$ \\
\hline At intubation & $92+5.6$ & $87+5.7$ & \\
\hline $\begin{array}{l}\text { Immediately } \\
\text { after intubation }\end{array}$ & $100+5.7$ & $91+5.8$ & \\
\hline $\begin{array}{l}1 \text { min after } \\
\text { induction }\end{array}$ & $98+5.4$ & $91+5.2$ & $<0.05$ \\
\hline $\begin{array}{l}3 \text { min after } \\
\text { induction }\end{array}$ & $97+5.7$ & $91+5.5$ & $<0.05$ \\
\hline $\begin{array}{l}5 \text { min after } \\
\text { induction }\end{array}$ & $96+5.7$ & $90+5.1$ & $<0.05$ \\
\hline
\end{tabular}

Mean arterial pressure was significantly reduced from 
baseline values post-induction and at the time of intubation in Group RS as compared to Group R $(\mathrm{P}=0.001)$. In Group $\mathrm{R}$, mean arterial pressure increased immediately after intubation, at 1 and $3 \mathrm{~min}$ after intubation, though statistically not significant. [Table 2]

Significant differences in heart rate and mean arterial pressure were seen immediately after intubation, at 1 and 3 min after intubation $(\mathrm{P}<0.05)$ between the two groups. Heart rate increased significantly $(\mathrm{P}<0.05)$ above baseline values immediately after intubation, at $1 \mathrm{~min}, 3 \mathrm{~min}$ and 5 min after intubation in Group R as compared to Group RS. [Table 3]

\section{Discussion}

Rocuronium is derivative of vecuronium, differing from it at three positions on steroid nucleus. Rocuronium has got a rapid onset of action intermediate duration of action and is devoid of any clinically significant cardiovascular side effects at effective neuromuscular blocking doses which makes it a better agent for endotracheal intubation among non-depolarizing neuromuscular blocking drugs Potent inhalational anaesthetic like sevoflurane is known to potentiate the neuromuscular blocking effects of aminosteroid neuromuscular blocking agents. Our study was conducted to compare the intubating time and conditions of rocuronium with $2 \%$ sevoflurane. The two groups were comparable with respect to age, sex, weight and ASA grade. Some recent studies have concluded earlier acceptable intubating conditions with sevo urane under similar anaesthetic conditions in adult. ${ }^{[9]}$ The dose used is more than 2 times ED95. Cooper et al compared the intubating conditions with rocuronium $(0.6 \mathrm{mg} / \mathrm{kg})$ and succinylcholine $(1 \mathrm{mg} / \mathrm{kg}$ ) in 50 patients. In the study, $95 \%$ of patients generated clinically acceptable intubating conditions at $60 \mathrm{~s}$ and $100 \%$ patients at $90 \mathrm{~s}$ with rocuronium. Intubating conditions were excellent in all cases. They concluded that rocuronium can be used as a safe alternative to succinylcholine in RSI.

In present study time of onset of intubation was significant $\mathrm{P}$ $<$ 0.001]. Similar conclusions regarding onset time and intubating conditions were obtained from other studies. ${ }^{[8,9]}$ Wright et al. ${ }^{[10]}$ concluded that the onset time of rocuronium, in doses more than $0.8 \mathrm{mg} / \mathrm{kg}$ was comparable to that of succinylcholine $1 \mathrm{mg} / \mathrm{kg}$ at the adductor pollicis but was significantly delayed at the laryngeal adductors. Studies have found that effect of rocuronium $0.6 \mathrm{mg} / \mathrm{kg}$ was enhanced by 1.5 MAC of sevoflurane in comparison with isoflurane or propofol anaesthesia. ${ }^{[1]}$

In Present study Significant differences in heart rate and mean arterial pressure were seen immediately after intubation, at 1 and 3 min after intubation $(\mathrm{P}<0.05)$ between the two groups. Elderly patients being treated with rocuronium $0.9 \mathrm{mg} / \mathrm{kg}$ showed no clinically significant change in heart rate, arterial blood pressure or plasma catecholamine concentrations. ${ }^{[12]}$ Slight to moderate increase in heart rate after rocuronium injection may be attributed to either pain on injection or to its weak vagolytic effect. The heart rate increase may be controlled by the prior administration of fentanyl.

\section{Conclusion}

Rocuronium along with sevoflurane provides excellent intubating conditions in elective neurosurgeries in patients, this approach can be considered for rapid sequence intubation during anaesthesia in neurosurgical patients.

\section{References}

1. Minton MD, Grosslight K, Stirt JA. Increase in intracranial pressure from succinylcholine: Prevention by priornon-depolarizing blockade. Anesthesiology. 1986;65: 165-9.

2. Stevenson PH, Birch A A. Succinylcholine induced hyperkalemia inpatient with a closed head injury. Anesthesiology. 1979;51:89-90.

3. Savarese JJ, Caldwell JE, Lien CA, Miller RD. Pharmacology of muscle relaxants and their antagonists. In: Miller, (Editor), 6th ed. Philadelphia Churchill Livingstone; 2004;1:490.

4. Rao MH, Venkatraman A, Mallleswari R. Comparison of intubating conditions between rocuronium with priming and without priming: Randomized and double-blind study. Indian J Anaesth 2011;55:494-8.

5. Magorian T, Flannery KB, Miller RD. Comparison of rocuronium, succinylcholine, and vecuronium for rapid-sequence induction of anesthesia in adult patients. Anesthesiology 1993;79:913-8.

6. Viby-Mogensen J. Dose-response relationship and time course of action of rocuronium bromide in perspective. Eur J Anaesthesiol Supp 1994;9:28-32

7. Cooper R, Mirakhur RK, Clarke RS, Boules Z. Comparison of intubating conditions after administration of Org 9246 (rocuronium) and suxamethonium. Br J Anaesth 1992;69:269-73.

8. Dubois MY, Lea DE, Kataria B, Gadde PL, Tran DQ, Shearrow T. Pharmacology of rocuronium with and suxamethonium. J Clin Anaesth 1995;7:44-8.

9. Huizinga AC, Vandenbrom RH, Wierda JM, Hommes FD, Hennis PJ. Intubating conditions and onset of neuromuscular block of rocuronium (Org 9426); a comparison with suxamethonium. Acta Anaesthesiol Scand 1992;36:463-8

10. Wright PM, Caldwell JE, Miller RD. Onset and duration of rocuronium and succinylcholine at the adductor pollicis and laryngeal adductor muscles in anesthetized humans. Anesthesiology 1994;81:1110-5.

11. Lowry DW, Mirakhur RK, McCarthy GJ, Carroll MT, McCourt KC. Neuromuscular effects of rocuronium during sevoflurane, isoflurane, and intravenous anesthesia. Anesth Analg 1998;87:936-40.

12. Shorten GD, Uppington J, Comunale ME. Changes in plasma catecholamine concentrations and haemodynamic effects of rocuronium and vecuronium in elderly patients. Eur J Anaesthesiol 1998;15:335-41

Copyright: (C) the author(s), 2020. It is an open-access article distributed under the terms of the Creative Commons Attribution License (CC BY 4.0), which permits authors to retain ownership of the copyright for their content, and allow anyone to download, reuse, reprint, modify, distribute and/or copy the content as long as the original authors and source are cited.

How to cite this article: Cherayath JB, George J. Study of Efficacy of Sevoflurane with Rocuronium during Induction in Neurosurgical Patients. Acad. Anesthesiol. Int. 2020;5(1):64-66.

DOI: dx.doi.org/10.21276/aan.2020.5.1.13

Source of Support: Nil, Conflict of Interest: None declared. 